\title{
Erratum to: FIGARO: The new horizontal neutron reflectometer at the ILL
}

R.A. Campbell ${ }^{a}$, H.P. Wacklin, I. Sutton, R. Cubitt, and G. Fragneto

Institut Laue-Langevin - BP 156, 38.042 Grenoble Cedex 9, France

Original article: Eur. Phys. J. Plus (2011) 126: 107, DOI: 10.1140/epjp/i2011-11107-8

Received: 6 October 2015

Published online: 30 October 2015 - (C) Società Italiana di Fisica / Springer-Verlag 2015

Equation (4) was erroneously written as

$$
\left(\frac{1}{X_{2}}-\frac{1}{X_{1}}\right) \cdot k x^{\prime 2}+\left(\frac{\tan (\theta) \cdot\left(\frac{1}{X_{1}}-\frac{1}{X_{2}}\right)+X_{2}}{X_{1}-\frac{X_{1}}{X_{2}}}\right) \cdot x^{\prime}+\left(X_{1}-X_{2}\right) \cdot k=0
$$

while it should read

$$
\left(\frac{1}{X_{2}}-\frac{1}{X_{1}}\right) \cdot k x^{\prime 2}+\left(\left(\tan (\theta) \cdot\left(\frac{1}{X_{1}}-\frac{1}{X_{2}}\right)\right)+\left(k\left(\frac{X_{2}}{X_{1}}-\frac{X_{1}}{X_{2}}\right)\right)\right) \cdot x^{\prime}+\left(X_{1}-X_{2}\right) \cdot k=0 .
$$

While a text-processing error led to the wrong equation being included in the published article, the correct equation was in fact used in the stated calculation of $x^{\prime}$, i.e., $x^{\prime}=22.6 \mathrm{~mm}$ for $30 \AA$ neutrons with input values of $X_{1}=368 \mathrm{~mm}$, $X_{2}=2533 \mathrm{~mm}$ and $\theta=0.62^{\circ}$. The correct equation has also always been used in the COSMOS data reduction software for FIGARO.

We acknowledge the contribution of A. Nelson who alerted us to the fact that there was an error in eq. (4) of the original publication.

\footnotetext{
a e-mail: campbell@ill.eu
} 